\title{
Analysis of Reactive Injection Compression Molding by Numerical Simulations and Experiments
}

\author{
Giorgio Ramorino ${ }^{D}$, Silvia Agnelli, and Matteo Guindani \\ Department of Mechanical and Industrial Engineering, University of Brescia, Via Branze 38, 25123 Brescia, Italy \\ Correspondence should be addressed to Giorgio Ramorino; giorgio.ramorino@unibs.it
}

Received 9 August 2019; Accepted 22 January 2020; Published 18 February 2020

Academic Editor: Thomas J. Farmer

Copyright (C) 2020 Giorgio Ramorino et al. This is an open access article distributed under the Creative Commons Attribution License, which permits unrestricted use, distribution, and reproduction in any medium, provided the original work is properly cited.

\begin{abstract}
Injection compression molding is an injection molding process with the addition of a compression stage after the injection. This process is useful for the injection molding of precision parts. A stable and controlled manufacturing process is needed to guarantee reliability of complex products, and usually process optimization is achieved by experimental and time consuming approaches. However, for being competitive a minimal market time is a very important requirement and computer simulations can help to optimize the process at the only expense of computational time. This paper reports and discusses for the first time the results of a 3D finite element simulation of reactive injection compression molding (RICM) by commercial software for the production of rubber diaphragms. In particular, the stages of mold filling dynamics and material curing are analyzed and the results verified with experimental tests. To get an accurate representation of the process, the rheological behavior, thermal properties, and kinetic behavior during curing of the real rubber compound were described by mathematical models. A differential scanning calorimeter (DSC) and a capillary rheometer are employed to characterize the rubber material in order to achieve an appropriate curing reaction and viscosity models, respectively. The computations are found to be in good agreement with the experimental results, indicating that reliable information on material viscosity and curing kinetics can play a key role in making well-founded predictions and avoiding trial and error methods.
\end{abstract}

\section{Introduction}

Many rubber articles are produced by molding, a process in which uncured rubber, sometimes with an insert of plastic or metal, is cured under pressure in a mold. Determining the right process for part production is a crucial step in the ultimate success of a product. There are three general molding techniques for rubber: compression, transfer, and injection molding. The choice of the best process is based on a number of key factors, including: the size and shape of the part, the hardness, flow and cost of the material, and the number of rubber parts to be produced [1-3].

Injection compression molding (ICM) [4] is a molding process which combines conventional injection molding and compression molding and has been developed to incorporate the advantages of both molding processes.
Rubber compression molding (RCM) [5, 6] is a process where preheated rubber is placed in a heated mold cavity (single or multicavity). Once closed off or reassembled, pressure is applied to the mold forcing the rubber material into contact with all internal surface areas. Then the heat and pressure are continuously applied until the rubber has cured. Compression molds vary considerably in size, shape, and complexity and also contain from one to a very high number of cavities. Compression molding is often chosen for medium hardness compounds-in high volume production or in applications requiring particularly expensive materials. It requires inexpensive tooling but it is a labor-intensive process with loading and process times longer than other molding methods.

Rubber injection molding (RIM) [7] is normally the most automated of the molding processes. The material is 
heated to a flowing state and injected under pressure from the heating chamber through a series of runners or sprues into the mold. Generally, parts manufactured using injection molding need additional treatments such as cryodeflashing and surface treatments to reduce the coefficient of friction. However, with some types of moulds it is possible to obtain finished parts that do not require additional finishing. The process is used for high production runs and parts that require tighter tolerances.

The schematic of the RICM (rubber injection compression molding) process used in this work is illustrated in Figure 1. Before the injection stage, the thickness of the mold cavity is set to be slightly larger than the nominal thickness of the part. This thicker cavity allows the polymer melt to flow into the mold cavity under low injection pressure. By closing the mold halves, the mold cavity thickness is reduced to the final part thickness. Injection compression molding has the advantages of decreasing molding pressure, reducing residual stress, minimizing molecular orientation, even packing, reducing uneven shrinkage, preventing sink marks and warpage, reducing density variation, and increasing dimensional accuracy.

Because of these advantages, injection compression molding is often employed to produce plastic parts of high accuracy dimensions and free of residual stress, especially for optical components [8-17]. However, the simulation of injection compression molding is very challenging due its complexity in terms of material data and process sequence. For the first time, this paper shows the results of a simulation of RICM process for rubber components.

Given that the rubber exhibits extremely complicated thermoviscoelastic material properties, the complexity of the model process makes it very challenging to attain the desired properties of parts and thus it is difficult to maintain part quality during production. One way researchers have found to improve the efficiency of this process is Computer Aid Engineering (CAE). Computer simulations allow increasing the final quality of the product by the correct selection of the technological parameters during rubber processing and, at the same time, obtaining significant savings by the project of an adequate period of the production cycle. In spite of the relevance of this tool, there are no literature works on the simulation of the RICM process for rubber.

This paper reports and discusses for the first time the results of the $3 \mathrm{D}$ finite element simulation of reactive injection compression molding (RICM) for the production of rubber diaphragms. Simulation is carried out using the "Reactive Molding" module of the Autodesk Moldflow 2018 CAE software, and the results are validated via the comparison with experimental tests. A very thin rubber diaphragm with complex geometry used in engineering was selected for this study. The mold filling dynamics in the injection and compression stages during the processes were analyzed. The representation of the filling progress is one of the most important outputs in order to identify weld lines and places where air bubbles may form. Finally, processing conditions, including compression stroke and compression speed, were investigated with a view to reducing the cavity pressure.
A successful injection molding simulation requires understanding of the actual material behavior and its description in the simulation using suitable material models. Because of the complex formulation of rubber compounds and the high degree of customization, there are problems associated with the use of existing material data sets from commercially available databases. For this reason, proper measurements of material viscosity and curing rate are required in order to run a simulation. A differential scanning calorimeter (DSC) and a capillary rheometer are employed to characterize the rubber material in order to obtain appropriate curing reaction and viscosity models, respectively, following an experimental approach already developed by the authors for the simulation of injection molding process [18]. The model parameters thus obtained are used to simulate the injection compression molding process.

\section{Experimental Characterization of the Material}

2.1. Material. In this study, the experimental investigations are carried out on an acrylonitrile butadiene rubber (NBR). The compound with NBR with $33 \%$ of nitrile content, a sulphur-based curing system and 30 wt.\% of carbon black, was provided by Ligom srl (Grumello del Monte, Bergamo, Italy). The specific compound formulation and preparation is not disclosed due to commercial reasons. The base material is indicated in this work as NBR60, since after complete vulcanization, it has a hardness of 60 Shore A and 59.4 IHRD. Hardness Shore A measurements were performed on $6 \mathrm{~mm}$ plates, according to ISO 7619-1:2010. IRHD hardness measurements were performed on $2 \mathrm{~mm}$ plates, according to ISO 48:2010.

2.2. Rheological Characterization. In order to characterize the rheological behavior, the flow curves of the rubber compound were obtained at different temperatures by a Rheologic 5000 Twin-Bore capillary rheometer by CEAST. Rheological measurements were performed with the NBR compound prepared without curatives, to avoid obstruction of the capillaries, particularly at high temperatures. The apparent viscosity data versus the apparent shear rate data were calculated for temperatures of 130,150 , and $170^{\circ} \mathrm{C}$. Bagley [19] and Rabinowitsch [20] corrections were applied to calculate the adjusted viscosity data.

The reactive viscosity model $[18,21-23]$ is used to describe the rheological properties of rubber compounds in the Plastics Insight (MPI) Reactive Molding Moldflow software in order to simulate the mold filling dynamics. The Reactive Viscosity Model is given by

$$
\begin{aligned}
\eta & =\frac{\eta_{0}(T)}{1+\left[\eta_{0}(T \gamma) / \tau^{*}\right]^{(1-n)}} \times\left(\frac{\alpha_{g}}{\alpha_{g}-\alpha}\right)^{C_{1}+C_{2} \alpha}, \\
\eta_{0} & =B \exp \left(\frac{T_{b}}{T}\right)
\end{aligned}
$$

where $\eta$ is viscosity, $\eta_{0}$ is "zero viscosity," that is, viscosity at low shear rates, $\gamma$ is the shear rate, $\tau^{*}$ represents the stress 
(a) Initial compression gap

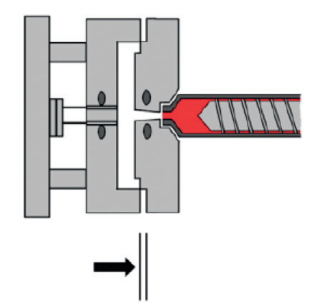

(b) Polymer melt injected into a pre-enlarged cavity

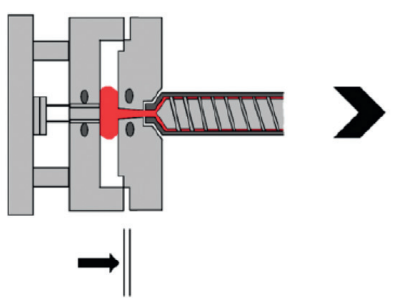

(c) Polymer melt compressed by clamping movement of machine

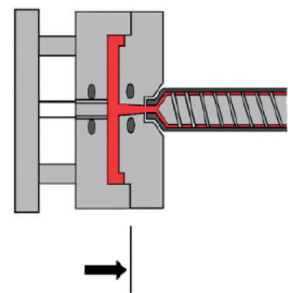

FIgURE 1: Schematic of the RICM process.

level at the transition between Newtonian and power law regions, $\alpha$ is the degree of cure, $a_{g}$ is the degree of curve at gelation point, $C_{1}$ and $C_{2}$ are fitting parameters, $B$ and $T_{b}$ are fitting parameters, and $T$ is the temperature. The terms $C_{1}$ and $C_{2}$ were set to 1 and 0 on the basis that the rubbers used in this work did not cure during the filling phase. $\alpha$ is the degree of cure, and the gelation conversion $\left(a_{g}\right)$ was set to 0.1 as a default value.

The parameters $\tau^{*}, n, B$, and $T_{b}$ were calculated using Origin software. Since the rheological tests were performed on compounds without cross-linking agents, only the parameters concerning the shear rate dependence of viscosity were determined from the experimental data. It should be pointed out that experimental viscosity data were measured in a range of logarithmic shear rate from about 1.3 to $31 / \mathrm{s}$, the typical range of the capillary rheometer. This experimental method was chosen since it is able to simulate the process conditions of high shear rate, pressure, and high shear exerted on the compound during the injection phase and during the final stages of mold closure. Moreover, as in the injection phase, the flow in the capillary is (nearly) fully developed, and the filler-filler structures are destroyed. Probably the simulation could be even more accurate adding viscosity data at lower strain rates. However, to obtain such data other types of experimental tests should be performed, such as dynamic mechanical tests, which however do not reproduce the fully developed flow. Therefore, in this work it was decided to keep the characterization as simple as possible. Deeper understanding could be obtained with other test methods; this will be the topic of future works.

Table 1 indicates the values obtained for these parameters and Figure 2 shows the good agreement between the experimental sets of data of viscosity, evaluated at different shear rate values and at temperatures of 130,150 , and $170^{\circ} \mathrm{C}$ (open symbols) and the respective curves generated by the Reactive Viscosity Model (lines).

2.3. Cure Kinetics Characterization. The curing of the material was defined in terms of the induction and cure kinetics and was experimentally characterized by DSC analyses. DSC analysis is an alternative technique to curemeter methods, as pointed out in previous literature works [24, 25]. Heat Flux DSC from TA Instruments was used. Isothermal tests were performed at $140,150,160$, and $170^{\circ} \mathrm{C}$. This test generates a profile of $\mathrm{dQ} / \mathrm{d} t$ versus time. The induction time is assumed to be the time at which the baseline cuts the exotherm curve.
TABLE 1: Parameters of the reactive viscosity model for the NBR60 compound.

\begin{tabular}{lc}
\hline$\tau^{*}(\mathrm{~Pa})$ & 22330.3 \\
$N$ & 0.11 \\
$B(\mathrm{~Pa} . \mathrm{s})$ & 10.3 \\
$T_{b}(\mathrm{~K})$ & 4325.5 \\
$C_{1}$ & 1 \\
$C_{2}$ & 0 \\
$a_{g}$ & 0.1 \\
\hline
\end{tabular}

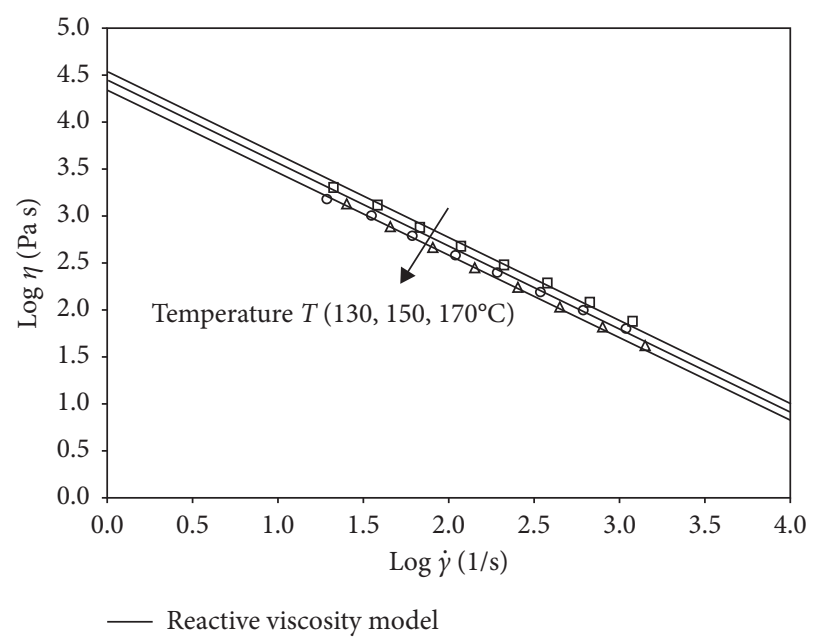

FIgURE 2: Experimental data of viscosity, evaluated at the temperatures of 130,150 , and $170^{\circ} \mathrm{C}$ (open symbols) and the respective curves generated by the reactive viscosity model (lines).

During this time, no chemical reaction takes place inside the rubber. The degree of cure (from 0 to 1 ) can be calculated using the following equation:

$$
\alpha(t)=\frac{\Delta H_{t}}{\Delta H_{T}} .
$$

The data of $t_{i}(T)$, obtained from each isothermal DSC test, are used to obtain the two constants $\left(B_{1}\right.$ and $\left.B_{2}\right)$ of the Claxon-Liska model to characterize the induction time of the NBR compound [26, 27]:

$$
t_{i}(T)=B_{1} \exp ^{\left(B_{2} / T_{0}\right)} .
$$

The rate of cure values $(\mathrm{d} \alpha / \mathrm{d} t)$ as a function of cure degree $\alpha$ shown in Figure 3 is easily calculated from the plots of $\alpha$ versus $t$ (cure kinetics curve) shown in Figure 4. 


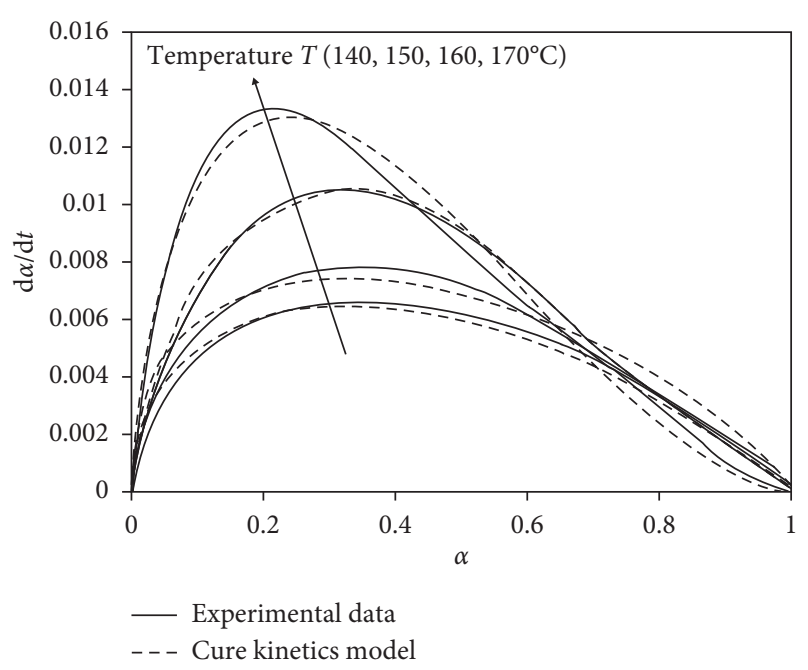

Figure 3: The rate of cure values $(\mathrm{d} \alpha / \mathrm{d} t)$ as a function of cure degree evaluated at different temperatures ( - experimental data; --- curve generated by cure kinetics model).

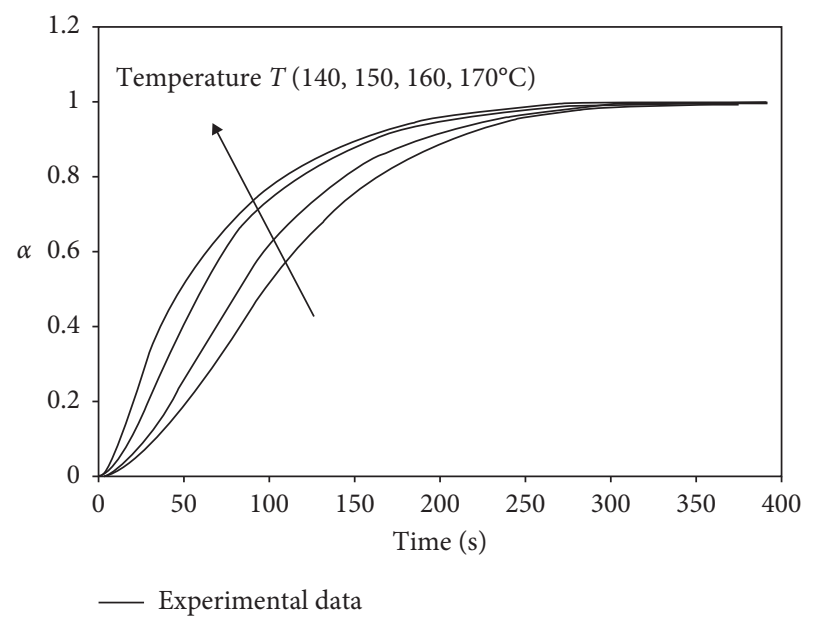

FIGURE 4: Cure kinetics curves: cure degree $\alpha$ as a function of time (s) evaluated at different temperatures $\left(140,150,160\right.$, and $\left.170^{\circ} \mathrm{C}\right)$.

These data are used to obtain the constants of the KamalSourour model [28] to characterize the cure kinetics of the material. In fact, Kamal and Sourour proposed that

$$
\begin{aligned}
& \frac{\mathrm{d} \alpha}{\mathrm{d} t}=\left(K_{1}+K_{2} \alpha^{m}\right)(1-\alpha)^{n}, \\
& K_{1}=A_{1} \exp \left(\frac{-E_{1}}{R T}\right), \\
& K_{2}=A_{2} \exp \left(\frac{-E_{2}}{R T}\right),
\end{aligned}
$$

where $K_{1}$ and $K_{2}$ are functions of the temperature and are defined by $m, n, E_{1}$, and $E_{2}$ parameters. $m$ and $n$ are reaction orders; $E_{1}$ and $E_{2}$ are the activation energies; $R$ is the gas universal constant parameter, with a value of $8.31 \mathrm{~J}(\mathrm{~mol} * \mathrm{~K})$. Data measured from DSC tests were fitted to this model with Origin software and reported in Table 2.
TABLE 2: Cure parameters defined for the NBR compound.

\begin{tabular}{lc}
\hline$B_{1}(\mathrm{~s})$ & $1.2 \times 10^{-5}$ \\
$B_{2}(\mathrm{~s})$ & 6642 \\
$A_{1}\left(\mathrm{~s}^{-1}\right)$ & 0 \\
$E_{1} / R(\mathrm{~K})$ & 0 \\
$A_{2}\left(\mathrm{~s}^{-1}\right)$ & $4.26 \times 10^{8}$ \\
$E_{2} / R(\mathrm{~K})$ & 10082 \\
$M$ & 0.535 \\
$N$ & 1.273 \\
\hline
\end{tabular}

The model parameters reported in Tables 1 and 2 are used to simulate the injection molding process including the stages of the mold filling dynamics and material curing of the rubber component. To evaluate the specific heat of reaction, nonisothermal DSC scans are taken at a fixed heating rate of $10^{\circ} \mathrm{C} / \mathrm{min}$ within the temperature range $70-220^{\circ} \mathrm{C}$. A typical DSC trace is shown in Figure 5 where an exothermic reaction peak is observed. The specific heat of reaction $H(\mathrm{~J} / \mathrm{g})$, as determined by the value of the peak area (A) divided by the mass of the sample (about $16 \mathrm{mg}$ ), is $H=11.64 \mathrm{~J} / \mathrm{g}$.

Thermal conductivity of the NBR compound is taken equal to $0.4 \mathrm{~W} / \mathrm{m} / \mathrm{K}$ and is calculated as average value of thermal conductivities reported both in the literature and in the software database for NBR compounds.

\section{Simulations and Discussions}

3.1. Part Geometry and Simulation by CAE (Computer Aided Engineering). The geometry of the rubber diaphragm part shown in Figure 6(b) is obtained after trimming the molded shoot (mold cavity) shown in Figure 6(c). This component is characterized by a complex geometry with a thickness distribution that ranges from $0.18 \mathrm{~mm}$ to $0.85 \mathrm{~mm}$. The 3DCAD drawing of the multicavity mold was exported to the FE software in STEP format and modelled using Autodesk Moldflow 2018.

In the numerical modeling and simulation, a circular sector with an angle of $90^{\circ}$ is chosen as the computational domain. Since the geometry of the component is circular and the injection location is exactly in the centre, a radial filling is expected. In order to limit the number of elements and thus the calculation time, we chose to simulate just a slice of the part. The slice was chosen large enough to be representative of the filling of the entire part; therefore, with the exception of the lateral boundaries of the slice, the filling in it can be considered as axisymmetric for the other slices of the part. Figure 6(d) shows the computational domain with the relative boundary conditions. In compression type molding process simulations, the surface of the model must be assigned the "compression surface" property type so the software can identify where compression will occur. The compression (moving) surface, green in Figure 6(d), is considered to be the press side of the cavity and will follow the press movement exactly while the fixed surface (yellow in Figure 6(d)) is considered to be the fixed side of the cavity. No movement occurs during compression. The domain is discretized by about $1,500,000$ tetrahedral elements (Figure 6(a)) with minimum 6 elements in the thickness 


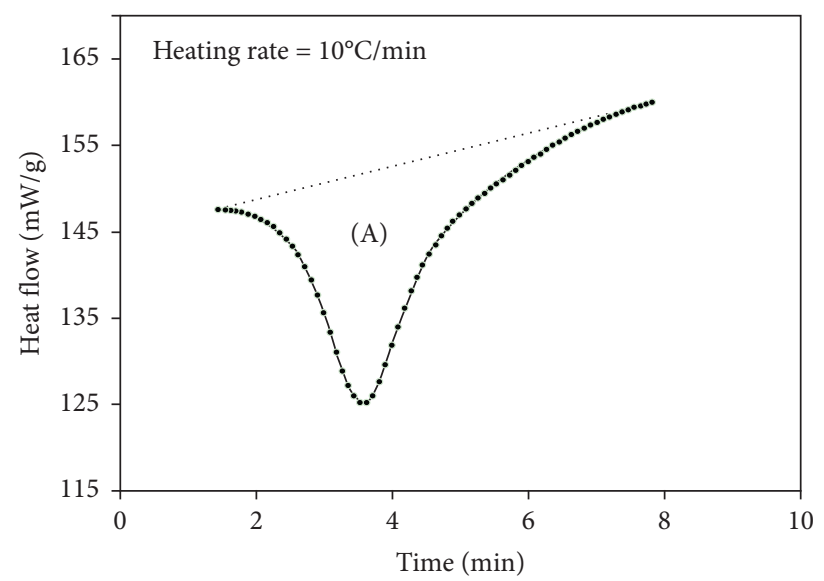

FIgURE 5: Trace of a DSC thermogram obtained at a heating rate of $10^{\circ} \mathrm{C} / \mathrm{min}$ within the temperature range $70-220^{\circ} \mathrm{C}$ for $\mathrm{NBR}$ compound.

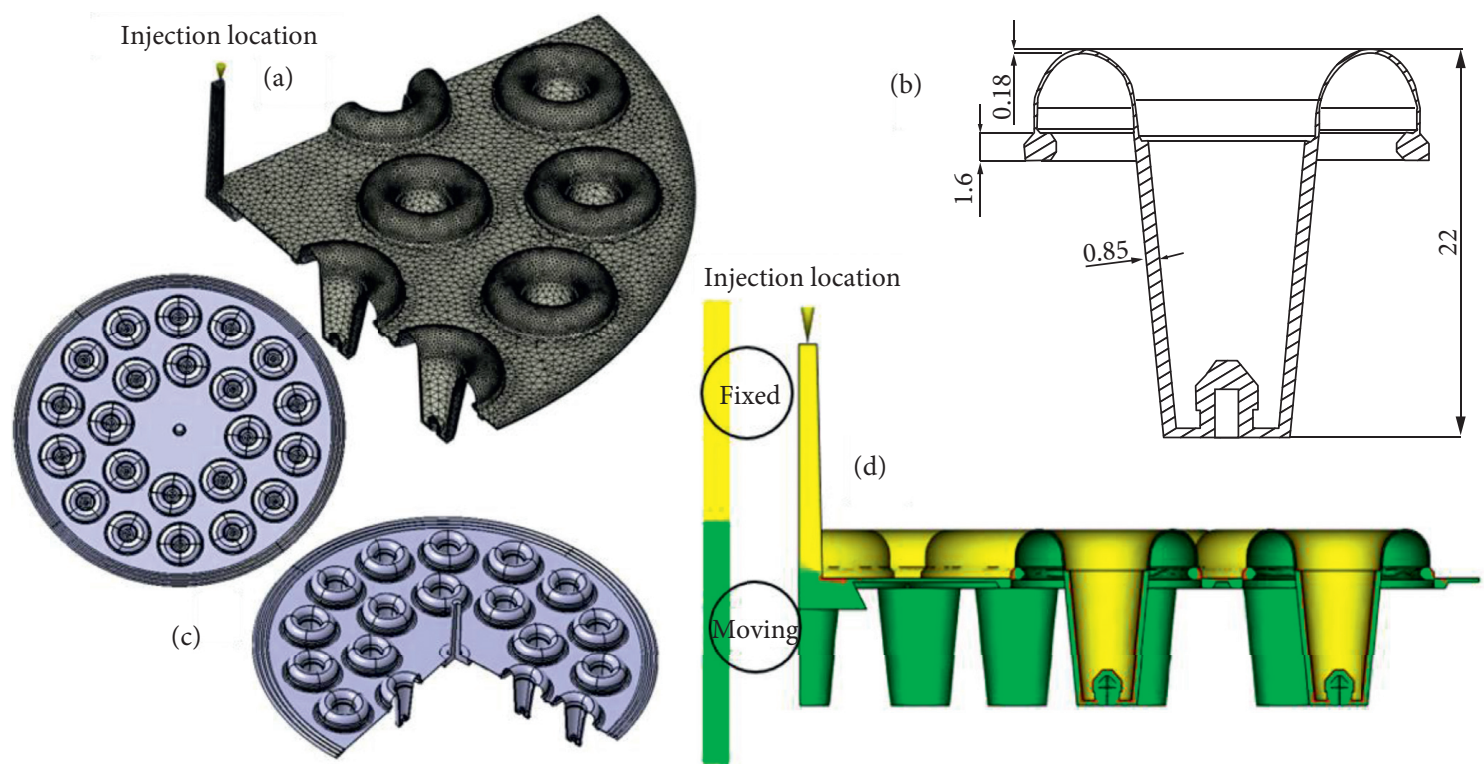

FIGURE 6: (a) 3D mesh of the circular sector with an angle of $90^{\circ}$; (b) geometry of the rubber diaphragm (dimensions in (mm)); (c) 3D representation of the complete injection shot (mold cavity); (d) compression moving (green) and fixed (yellow) surfaces.

direction, which has been selected after a mesh statistics test. For a given compression speed, the mesh system is deformed and a new configuration is formed at every time stage. Then the nodal coordinate values and other auxiliary quantities are updated to obtain new velocity, pressure, and temperature, at each time stage.

3.2. Process Settings. In the reactive compression-injection process, the cavity thickness is initially greater than the target thickness and the rubber is injected into the cavity at a user-defined injection velocity. At the velocity-pressure switchover time, the pack phase starts, following a userdefined packing profile, and regardless of when press compression is programmed to start. Meanwhile, the press is moved to a predetermined position. It will be stationary and stay in this position for a period of time. The waiting time starts when the injection begins and ends when the press
TABLE 3: Main process parameters.

\begin{tabular}{lc}
\hline Injection time $(\mathrm{s})$ & 2 \\
Injection temperature $\left({ }^{\circ} \mathrm{C}\right)$ & 70 \\
Mold temperature $\left({ }^{\circ} \mathrm{C}\right)$ & 170 \\
Cure time $(\mathrm{s})$ & 210 \\
Press open distance $(\mathrm{mm})$ & 6.3 \\
Volumetric flow rate $($ injection$)\left(\mathrm{cm}^{3} / \mathrm{s}\right)$ & 13.2 \\
Press compression speed $(\mathrm{mm} / \mathrm{s})$ & 3 \\
Press compression start $(\%$ volume filled) & 100 \\
Max press compression force $(\mathrm{N})$ & $2.94 * 10^{6}$ \\
\hline
\end{tabular}

begins to move. The compression stage starts when the press begins to move. In the press compression stage, the movement of the press initially takes place under speed control, specified by the press compression speed at incremental distances profile. The press can keep moving forward; however, it will be in a constant force control mode (preset force). Finally, after the press compression phase is 


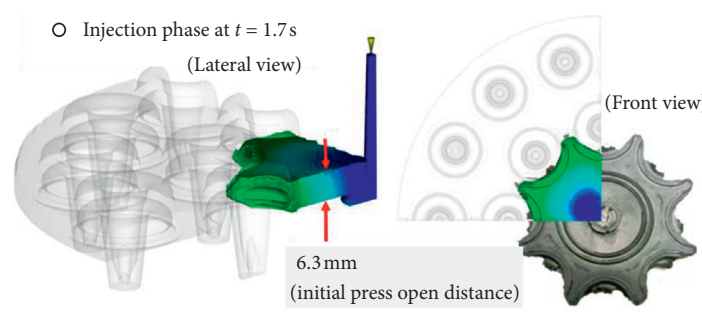

(a)

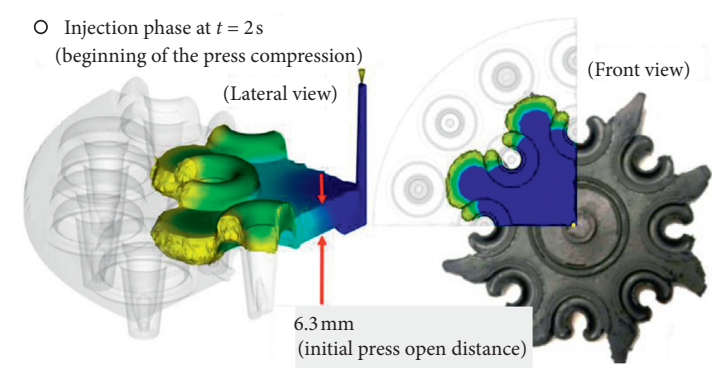

(b)

FiguRE 7: Results of the filling patterns obtained from simulation (Fill Time) and the corresponding incomplete molded part obtained through interrupted filling experiments at $1.7 \mathrm{~s}$ (a) and $2 \mathrm{~s}$ (b) of Fill Time. In both cases, the initial press open distance is $6.3 \mathrm{~mm}$.

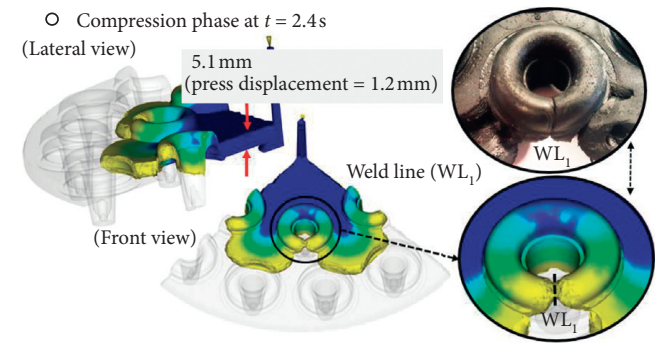

(a)

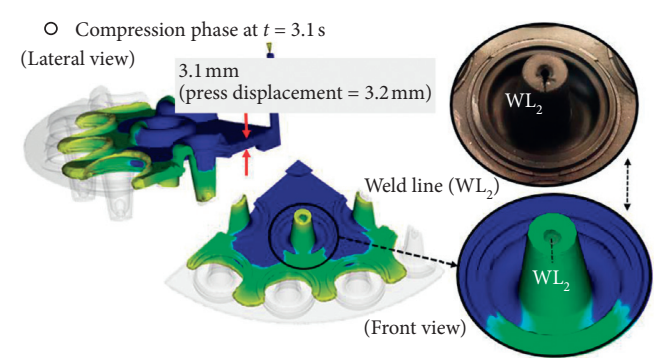

(b)

FIGURE 8: Results of the filling patterns obtained from simulation (Fill Time) and the corresponding incomplete molded part obtained through interrupted filling experiments during the compression phase. The initial press open distance is $1.2 \mathrm{~mm}$ (a) and $3.2 \mathrm{~mm}$ (b).

completed, the press will stay in that position and remain stationary for the specified curing time.

In order to verify the reliability of the flow simulation, the results of the simulation were compared to the results of experimental tests carried out under the same conditions of industrial production. In particular, a 300-ton MIR horizontal molding machine was used for the experiments. The same parameters used in the experimental test, including compression speed, switch time from injection to compression, and compression stroke, were used also in the simulation. Table 3 shows the main process parameters used for the computer simulations. The initial melt temperature is $70^{\circ} \mathrm{C}$, the mold temperature is $170^{\circ} \mathrm{C}$, and the initial press open distance is $6.3 \mathrm{~mm}$. Both initial melt and mold temperature were experimentally checked with a thermocouple. Melt temperature, measured on rubber purging, was in the range $70 \pm 4^{\circ} \mathrm{C}$, and mold temperature was measured in several locations and resulted to oscillate in the range $170 \pm 3^{\circ} \mathrm{C}$. The temperature variations were hypothesized to have negligible effects on the results of the simulation; therefore the average temperature values were set as parameters. The press moves at a constant speed (at $3 \mathrm{~mm} / \mathrm{s}$ ) until switch over to force control. The volumetric flow rate for the injection phase equals $13.2\left(\mathrm{~cm}^{3} / \mathrm{s}\right)$.

3.3. Mold Filling Dynamic. In Figure 7, we compare the results of the filling patterns obtained from Moldflow simulation (Fill Time) and the corresponding incomplete molded part obtained through interrupted filling experiments at the initial press open displacement of $6.3 \mathrm{~mm}$. The Fill Time shows the position of the flow front at regular intervals as the cavity fills. The amount of melt inside the cavity before compression was set in advance, so that the volume of the material would be exactly the same as the part volume. A movable mold wall was used to compress the melt, which had previously partially filled in the cavity. As mentioned earlier, one of the most important outputs is the representation of the filling progress in order to identify weld lines and places where air bubbles may form.

Figure 8 shows the comparison between the pictures of the incomplete molded parts and the corresponding filling patterns predicted by computer simulation during the compression phase and the respective weld-line position $\left(\mathrm{WL}_{1}\right.$ and $\left.\mathrm{WL}_{2}\right)$. The agreement appears remarkable, suggesting that the predictions are representative of the flow during the filling stage. Figure 9 shows the final condition at the end of press compression and the real part obtained after trimming.

3.4. Curing Kinetics. In order to compare the results in terms of curing kinetics, the experimental degree of cure of the component after injection molding was experimentally evaluated by DSC. Interrupted filling experiments were carried out at various cure times. Parts were taken out of the mold, and specimens were cut out from parts in zones defined as A in Figure 10. The specimens were analyzed by nonisothermal DSC scans with the same conditions of the 


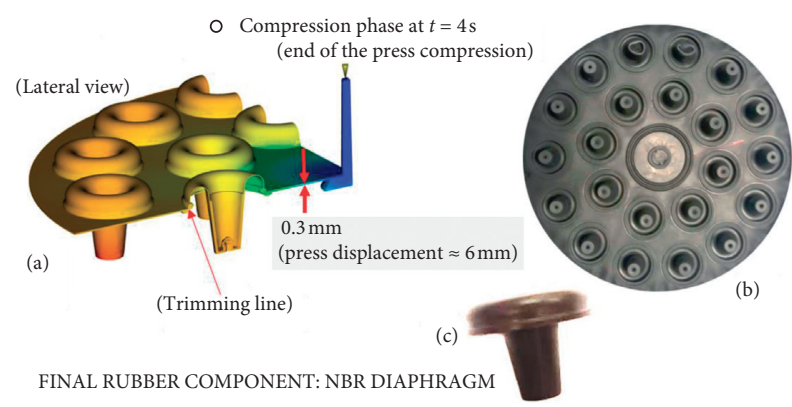

FIGURE 9: Final condition at the end of press compression (a) and the real part (c) obtained after trimming the molded part (b).

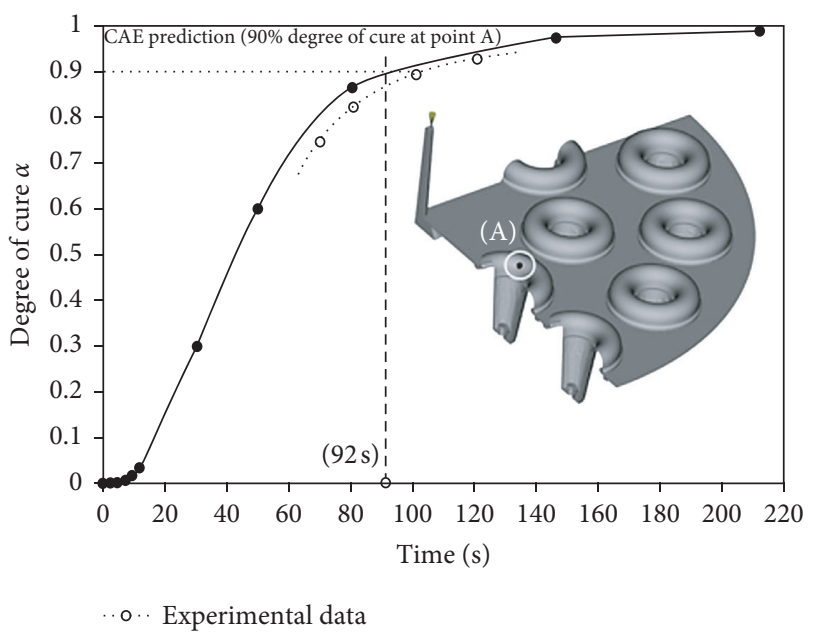

Figure 10: Comparisons of simulated degree of cure a versus time with that obtained from experimental measurements (measurements were made only in zones defined as A).

uncured sample (see paragraph 2.3). The degree of cure was calculated with the following relationship:

$$
\alpha=\frac{\left(\Delta H_{t 1}-\Delta H_{t 2}\right)}{\Delta H_{t 1}},
$$

where $\alpha$ is the degree of cure, $\Delta H_{t 1}$ is the exothermicity for the uncured sample, and $\Delta H_{t 2}$ is the exothermicity of the sample cured during time $t$.

If the sample is completely cured, the enthalpy will be zero, whereas for partially cured samples, an intermediate value will be obtained. The results of comparisons of the experimental cure curve with that predicted by simulations are shown in Figure 10; measurements were made only in zones defined as A. The experimental points are measured at times compatible with experimental practice: usually components are undercured and the curing reaction is completed in a postcuring phase out of the mold. Therefore the risk of reversion and of consequent decay of rubber properties is prevented both by the short process times and by the material, which does not show reversion. It was clearly observed that the cure kinetics predicted by the simulations showed faster cure profiles than those obtained in reality. In any case, to obtain good vulcanization, assumed as $90 \%$ average degree of cure, the software predicts $92 \mathrm{~s}$, which is in good agreement with the data obtained through the DSC test (100s).

\section{Conclusions}

The injection compression molding process for rubber diaphragms, including the stages of the mold filling dynamics and material curing, was modelled virtually for the first time. The virtual results were verified in real injection molding tests. A process optimum was successfully found that ensures both component quality and the highest possible economic efficiency. The simulation turned out to be a reliable and effective tool to predict potential defects as weld lines. Correct measurement and modeling of the material behavior were essential for successful use of the model. Further improvements in the approach could further improve the accuracy of results. The improvements concern the following parameters: (i) boundary conditions, such as mold and melt temperature, whose variability could be taken into account in the simulation; (ii) experimental viscosity characterization covering also low shear rate values, to better simulate the compression phase; and (iii) mold surface roughness, which could affect filling phase particularly in case of thin sections.

\section{Data Availability}

The experimental and numerical data used to support the findings of this study are available.

\section{Conflicts of Interest}

The authors declare that there are no conflicts of interest regarding the publication of this paper.

\section{Acknowledgments}

The research was financially supported by the University of Brescia, Department of Mechanical and Industrial Engineering.

\section{References}

[1] M. R. Kamal and M. E. Ryan, Injection and Compression Molding Fundamentals, A. I. Isayev, Ed., Marcel Dekker, New York, USA, 1987.

[2] J. A. Lindsay, Practical Guide to Rubber Injection Moulding, Smithers Rapra Technology, Shrewsbury, UK, 2012.

[3] V. Walworth, Rubber Molding Principles, TechnoBiz Communication Co., Ltd., Bangkok, Thailand, 2013.

[4] O. Solorza-Nicolas, H. Hernandez-Moreno, O. SusarreyHuerta, and N. Romero-Partida, "Film-insert injection compression molding for reinforced polycarbonate with woven glass fiber oriented $90 / 0^{\circ}, \pm 45^{\circ}$," Polymer Engineering and Science, vol. 59, no. 2, pp. E372-E379, 2019.

[5] K. Maghsoudi, G. Momen, R. Jafari, and M. Farzaneh, "Direct replication of micro-nanostructures in the fabrication of superhydrophobic silicone rubber surfaces by compression molding," Applied Surface Science, vol. 458, pp. 619-628, 2018.

[6] K. Maghsoudi, G. Momen, and R. Jafari, "Micro-nanostructured silicone rubber surfaces using compression 
molding," in Proceedings of the Thermec 2018: 10th International Conference on Processing and Manufacturing of Advanced Materials, vol. 941, pp. 1802-1807, Paris, FRANCE, July 2018.

[7] K. Kyas, M. Stanek, D. Manas et al., "Novel trends in rheology V," Book Series: AIP Conference Proceedings, vol. 1526, pp. 142-147, 2013.

[8] F. J. Parker, "Efficient processing of thermosets by injection moulding," Plast Rubber Process, vol. 3, no. 1, pp. 24-28, 1978.

[9] R. H. Schlueter, "Injection moulding methods," European Rubber Journal, vol. 164, no. 8, pp. 49-52, 1982.

[10] R. H. Schlueter, "Injection molding: review of non-traditional techniques and concepts," Elastomerics, vol. 113, no. 12, pp. 37-41, 1981.

[11] B. Friedrichs, M. Horie, and Y. Yamaguchi, "Simulation and analysis of birefringence in magneto-optical discs: part A-formulation," Journal of Materials Processing and Manufacturing Science, vol. 5, no. 2, pp. 95-113, 1996.

[12] B. Fan, D. O. Kazmer, R. P. Theriault, and A. J. Poslinski, "Simulation of injection-compression molding for optical media," Polymer Engineering \& Science, vol. 43, no. 3, pp. 596-606, 2003.

[13] M. R. Kamal, A. I. Isayev, S. J. Liu, and J. F. Agassant, Injection Molding: Technology and Fundamentals, Hanser, Cincinnati, OH, USA, 2009.

[14] W. Michaeli, S. Hessner, F. Klaiber, and S. Hebner, "Analysis of different compression-molding techniques regarding the quality of optical lenses," Journal of Vacuum Science \& Technology B: Microelectronics and Nanometer Structures, vol. 27, no. 3, p. 1442, 2009.

[15] S.-C. Chen, Y.-C. Chen, H.-S. Peng, and L.-T. Huang, "Simulation of injection-compression molding process, part 3: effect of process conditions on part birefringence," Advances in Polymer Technology, vol. 21, no. 3, pp. 177-187, 2002.

[16] H.-S. Lee and A. I. Isayev, "Numerical simulation of flowinduced birefringence: comparison of injection and injection/ compression molding," International Journal of Precision Engineering and Manufacturing, vol. 8, no. 1, pp. 66-72, 2007.

[17] W. Michaeli and M. Wielpuetz, "Optimisation of the optical part quality of polymer glasses in the injection compression moulding process," Macromolecular Materials and Engineering, vol. 284-285, no. 1, pp. 8-13, 2000.

[18] G. Ramorino, M. Girardi, S. Agnelli et al., "Injection molding of engineering rubber components: a comparison between experimental results and numerical simulation," International Journal of Material Forming, vol. 3, no. 1, pp. 551-554, 2010.

[19] E. B. Bagley, "The separation of elastic and viscous effects in polymer flow," Transactions of the Society of Rheology, vol. 5, no. 1 , pp. 355-368, 1961.

[20] B. Z. Rabinowitsch, "Über die viskosität und elastizität von solen," Journal of Physical Chemistry A, vol. 145, p. 1, 1929.

[21] Autodesk, Simulation Moldflow Insight, Fundamentals 2014, Student Guide-Practice Manual, Ascent, Charlottesville, VA, USA, 2013.

[22] Autodesk, Simulation Moldflow Insight, Advanced Flow 2014, Student Guide-Theory and Concepts Manual, Ascent, Charlottesville, VA, USA, 2013.

[23] J. M. Castro and C. W. Macosko, "Studies of mold filling and curing in the reaction injection molding process," AIChE Journal, vol. 28, no. 2, pp. 250-260, 1982.

[24] M. A. López-Manchado, M. Arroyo, B. Herrero, and J. Biagiotti, "Vulcanization kinetics of natural rubber-organoclay nanocomposites," Journal of Applied Polymer Science, vol. 89, no. 1, pp. 1-15, 2003.
[25] R. Ding, A. I. Leonov, and A. Y. Coran, "A study of the vulcanization kinetics of an accelerated-sulfur SBR compound," Rubber Chemistry and Technology, vol. 69, no. 1, pp. 81-91, 1996.

[26] W. E. Claxton and J. W. Liska, "Calculation of state of cure in rubber under variable time-temperature conditions," Rubber Age, vol. 95, no. 5, p. 237, 1964.

[27] A. Arrillaga, A. M. Zaldua, and A. S. Farid, "Evaluation of injection-molding simulation tools to model the cure kinetics of rubbers," Journal of Applied Polymer Science, vol. 123, no. 3 , pp. 1437-1454, 2012.

[28] M. R. Kamal and M. E. Ryan, "The behavior of thermosetting compounds in injection molding cavities," Polymer Engineering and Science, vol. 20, no. 13, pp. 859-867, 1980. 